\title{
Promoting Resilience While Mitigating Disease Transmission: An Australian COVID-19 Study
}

\author{
Freya M. Shearer, Niamh Meagher, Katitza Marinkovic Chavez, Lauren \\ Carpenter, Alana Pirrone, Phoebe Quinn, Eva Alisic, James M. McCaw, Colin \\ MacDougall, David J. Price and Lisa Gibbs
}

\begin{abstract}
In this Chapter, we present evidence to inform evolving COVID-19 response planning by analysing how Australians were thinking, feeling and behaving in response to the so-called "first wave" of the COVID-19 epidemic and the associated public health measures. These topics were explored through an online survey of Australian adults $(n=999)$ between 3-6 April 2020, less than one week after "stay-at-home" restrictions were enacted nationally to mitigate the spread of COVID-19. To explore if and how people's thoughts, feelings, and behaviours may have changed over time, we fielded the same survey between 28 April and 6 May 2020 ( $n=1020)$, with 732 respondents completing both surveys. Overall, our study found high levels of community acceptance and adherence to physical distancing measures. While physical distancing measures have proven highly effective at mitigating disease transmission worldwide, they have substantial social and economic costs. Our results highlight the negative social and emotional impacts of physical distancing and the importance of complementary policies that enable social connection and self- and collective efficacy to minimise these impacts and promote community resilience.
\end{abstract}

\subsection{Introduction}

Australians watched with concern when the novel coronavirus SARS-CoV-2 was first reported in Wuhan, China in December 2019 [1]. Concern turned to alarm as, by March 2020, the virus had spread to all global regions, and COVID-19 (the disease caused by SARS-CoV-2) was threatening to overwhelm some of the world's economies and strongest health systems $[2,3]$. In the absence of an effective treatment or vaccine for COVID-19, physical distancing measures soon formed the cornerstone of the global response - at a scale that was not typically contemplated by existing pandemic plans [4-8].

There is so much that is new about this pandemic that "unprecedented" soon became the most used word in formal and informal discussions about how to deliver a proportionate public health response. Indeed, in free text responses to our first survey (described later), respondents referred to it by emotive names such as "rotten", "disgusting", and "invisible". Some worried that scientists did not understand its basic biological processes.

This chapter presents evidence to inform continued, evolving response planning in Australia, and where relevant, in other countries around the world. It includes findings from two nationwide surveys $[9,10]$ asking the overall question: How were Australians thinking, feeling and behaving in response to the "first wave" of the COVID-19 epidemic and the associated public health measures? 
By doing so, we aim to guide decision-making on how best to manage disease transmission and promote community resilience.

Specifically, we provide insight into levels of transmission-reducing behaviours, how these changed over time, and how these behaviours related to people's concerns and perceptions. We explore how these trends differed between lower- and higher-impacted Australian states and territories.

Next, the chapter reports on the social and emotional impact of COVID-19 on Australians. Internationally, it is agreed that five elements are essential to support people and communities confronted with large scale-disaster and loss in the immediate and mid-term [11]. These elements, which also underpin Psychological First Aid [12, 13], are the promotion of: a sense of safety; calm; a sense of self- and community efficacy; connectedness; and hope. We conclude with insights into how these elements interacted with people's mental health and wellbeing during pandemic restrictions.

\subsection{Early Phase of the Australian Epidemic and the Public Health Response}

Australia has a federated political system featuring overlapping responsibilities between a federal government, eight state and territory governments and local governments. The political geography of Australia, as an island continent, has informed the shape of the responses. Over two decades, one of the most strident political positions for successive federal governments has been to use its authority to control the national borders to reduce the number of refugees arriving by boat to seek asylum in Australia. By contrast, the eight states and territories, with different climates, industry, population structures and geography, have their own powers to close borders to other jurisdictions. In response to COVID-19, a National Cabinet was quickly formed to improve communication, co-ordination across states and territories, and joint decision making.

The first case of COVID-19 was detected in Australia on 22 January 2020 [14]. On 1 February, when China was the only country reporting uncontained transmission, Australia closed its borders to mainland China [15]. Australia only reported 12 cases of COVID-19 through February. By contrast, globally the number of confirmed cases and geographic extent of transmission continued to increase drastically [16]. By early March, Australia faced the threat of importation from all global regions, and governments and health authorities were concerned when daily case counts rose sharply through the first half of March. Although more than two thirds of cases were connected to returned travellers who acquired their infections overseas, pockets of local transmission were reported in the cities of Sydney and Melbourne [17].

As a result, from 16 March 2020 the eight state and territory governments of Australia used their own authority to progressively implement physical distancing measures to prevent and reduce community transmission of SARS-CoV-2 [18]. By 29 March 2020, all Australians were strongly advised to leave their homes only for limited essential activities and public gatherings were limited to two people (known as "stay-at-home" restrictions). These measures were in addition to self-isolation advice for (mild) confirmed cases and their contacts, as well as for returned overseas travellers.

By late March, daily counts of new cases were declining, and the effective reproduction number was estimated to be below 1 [19], indicating that the collective actions of the Australian public and government authorities had successfully mitigated a first epidemic wave. Of the 7,075 confirmed cases of COVID-19 in Australia up to 17 May 2020, 70\% were acquired overseas [20]. 


\subsection{Understanding the Response of Australians to COVID-19}

To develop a timely understanding of how people in Australia were thinking, feeling, and behaving in relation to the COVID-19 pandemic and the associated response measures, we conducted two nationwide surveys.

The first survey was conducted online from 3 to 6 April, shortly after the activation of "stay-at-home" restrictions in response to the initial wave of imported infections, and the other three weeks later (29 April to 6 May) when restrictions remained in most state and territories (Figure 27.1). Western Australia commenced easing of restrictions on 27 April [21], followed by the Northern Territory and New South Wales on 1 May $[22,23]$. Note that all data were collected during the first epidemic wave, prior to the establishment of a second wave in the state of Victoria in late June 2020 [24].

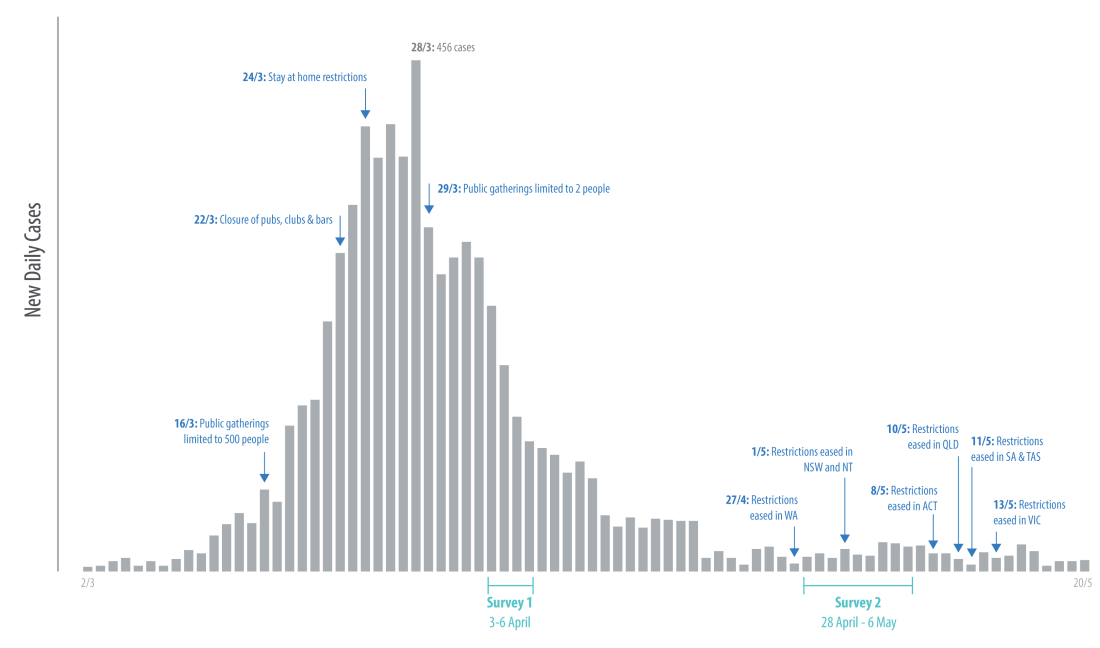

\section{FIGURE 27.1}

Plot of national daily new case notifications in Australia [25], timings of key national response policies and Surveys 1 (teal) and 2 (blue). Note: we include both overseas and locally acquired cases in the daily case counts. Of all cases in Australia notified up to 17 May 2020 with a known place of acquisition (95\%), $70 \%$ were acquired overseas [20]

\subsection{Overview of Data Collection and Analysis}

The sample size of Survey 1 was 999 Australian residents aged 18 years and over. The sample size of Survey 2 was 1020 individuals, of which $732(71.8 \%)$ had previously completed Survey 1. Results were weighted and are representative of the adult population in Australia (as described below).

The two surveys were based on research developed and conducted by Imperial College in the UK in mid-March 2020 [26]. Some questions in the Australian survey were modified slightly to reflect local response measures and terminology. Additional questions were added to the Australian survey to measure social and emotional impacts. Data collection in both the UK and Australia was conducted by the online market research agency YouGov.

We used a structured questionnaire addressing the following three domains: 
- perceptions of risk and consequences of COVID-19 infection;

- measures taken by individuals to protect themselves and others from COVID-19 infection; and

- social and emotional impact.

Finally, we included an open-ended question to allow people to express their main concern regarding the COVID-19 pandemic. The question requiring a free text response was: "What is your biggest concern at the moment?" All respondents answered the question as it was mandatory. We conducted thematic coding, informed by Framework analysis [27] which was designed to code qualitative data in order to inform policy and practice. The data reported here are primarily a sub-section of the total coding frame, designed to illustrate key points in the quantitative analysis.

The questionnaire was administered online to members of the YouGov Australia panel of individuals who have agreed to take part in surveys of public opinion (over 120,000 Australian adults). Panellists, selected at random from the base sample, received an email inviting them to take part in a survey, which included a survey link. Once a panel member clicked on the link and logged in, they were directed to the survey most relevant to them available on the platform at the time, according to the sample definition and quotas based on census data. A plain language statement appeared on screen and respondents were required to electronically consent prior to the survey questions appearing. Proportional quota sampling was used to ensure that respondents were demographically representative of the Australian adult population, with quotas based on age, gender, income and location (state and metropolitan or regional).

The study was by approved by the University of Melbourne Human Research Ethics Committee (2056694).

\subsection{Geographic Variation in COVID-19 Epidemiology and Public Health Response in Australia}

Our analyses differentiated between lower-impacted and higher-impacted jurisdictions because of the geographical variation in COVID-19 epidemiology and the associated physical distancing policies. Australia's two most populous states, New South Wales (more than 8.1 million people) and Victoria (more than 6.1 million people), also the most exposed to international travellers, experienced considerably higher total numbers of confirmed cases and peak daily incidence than other jurisdictions [14]. Consequently, people living in New South Wales and Victoria also experienced longer periods of restriction on their movement and social gatherings. New South Wales and Victoria are therefore defined as higher-impacted jurisdictions and all other jurisdictions as lower-impacted jurisdictions (Figure 27.2).

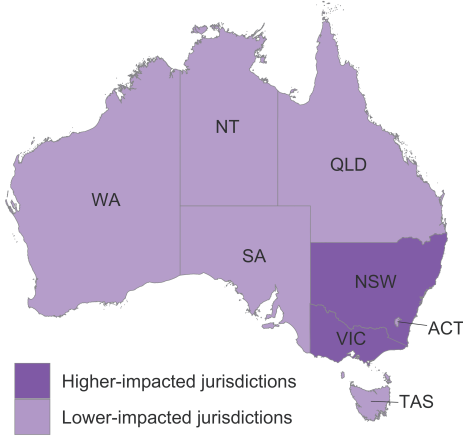

FIGURE 27.2

Map of the higher and lower impacted jurisdictions in Australia. 


\subsection{Findings}

\subsubsection{How did people perceive the risk and consequences of SARS-CoV-2 infection?}

Respondents perceived that their risk of SARS-CoV-2 infection decreased between the two survey periods, which coincided with a reduction in disease prevalence across Australia. Fewer respondents believed that it was likely they would be infected with SARS-CoV-2 at some point in the future at Survey $2(29.6 \%)$ compared to Survey $1(38.2 \%)$. This change was similar across lower- and higher-impacted jurisdictions.

There was little difference in perceived severity of SARS-CoV-2 infection between surveys. In both surveys, older adults were more likely than younger adults to believe that, if infected themselves, SARS-CoV-2 would be life-threatening or very severe (requiring hospitalisation). Respondents with a self-reported health status of "poor" or "fair" were also more likely to believe that, if infected, their infection would be very severe or life-threatening compared to those who reported being in "good", "very good", or "excellent" health. These self-assessments are consistent with risk profiles for COVID-19 where increasing age and comorbidities are associated with more severe outcomes [28]. Despite having different risk profiles, responses between males and females were very similar.

\subsubsection{How did people change their behaviours to prevent the spread of COVID-19?}

Overall, very high levels of physical distancing behaviour were reported at both Surveys 1 and 2 (Figure 27.3).
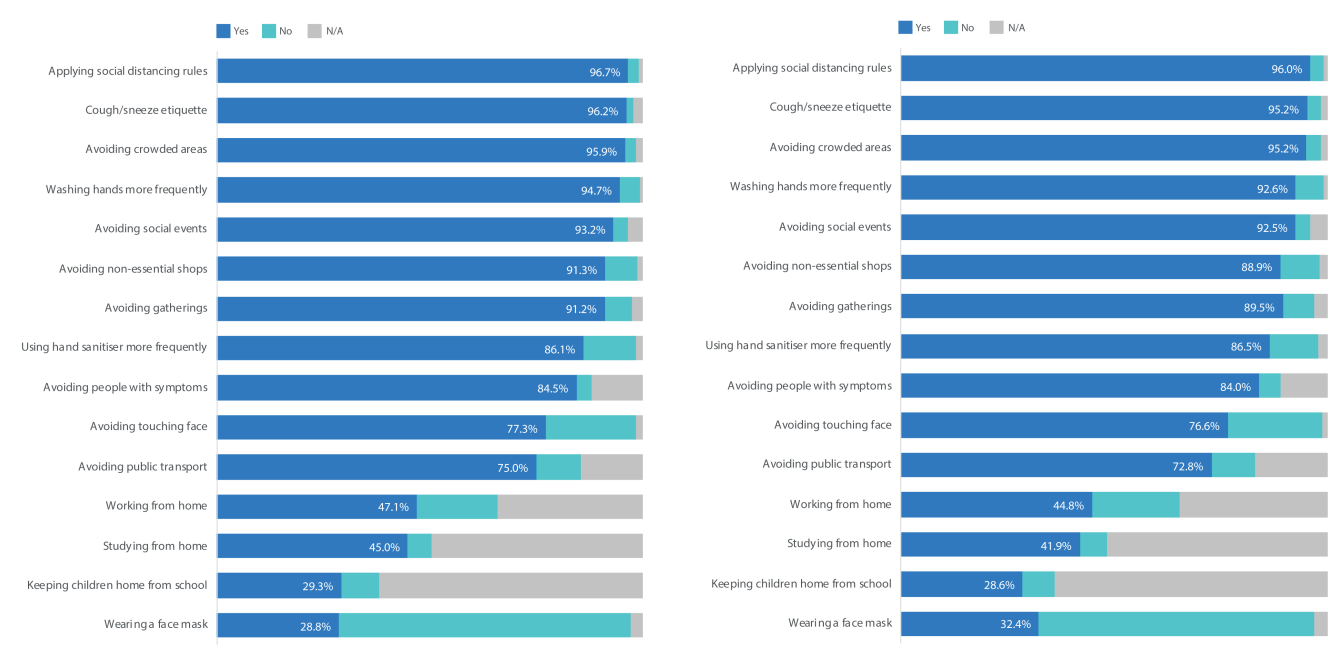

\section{FIGURE 27.3}

Percentage of respondents taking measures to protect themselves and others from SARS-CoV-2 infection at Surveys 1 (left) and 2 (right). Applying social distancing rules = "staying 1.5m apart, not shaking hands etc". Keeping children home from school = "keeping children home from school when schools are open". N/A = not applicable to me.

SARS-CoV-2 spreads via close contact between infectious and susceptible individuals. The rate of spread depends on a number of factors, including 1) the number of social contacts made 
by an infectious individual and 2) the nature of those encounters (how long they were, whether there was physical contact, whether they occurred indoors/outdoors). Both of these factors are impacted by changes in physical distancing behaviour. Accordingly, we used two types of physical distancing behaviour in our analyses. Firstly, behaviour that reduces the number of daily contacts made by an individual (excluding members of their household), such as working from home or avoiding social gatherings ("macro-distancing" behaviour). Secondly, behaviour that reduces the per contact probability of transmission such as handwashing, avoiding physical contact, and staying $1.5 \mathrm{~m}$ apart from others ("micro-distancing" behaviour). Distinguishing between these two types of behaviour and directly measuring them through population surveys has been critical to monitoring the transmission potential of SARS-CoV-2 [29].

In the longitudinal subsample, there was no meaningful difference in the percentage of respondents applying micro-distancing measures (keeping 1.5 metres away from others, not shaking hands, etc.) between Survey 1 (97.0\% [96\% CI: 95.9, 98.2]) and Survey 2 (96.5\% [95\% CI: 95.4, 97.9]). There was no meaningful change in the overall percentage of respondents washing their hands more frequently at Survey 2 (92.1\% [95\% CI: 90.3, 94.0]) compared to Survey 1 (94.6\% [95\% CI: 93.1, 96.2]).

Our results indicate that Australians reached high levels of self-reported adherence to micro-distancing measures recommended in March 2020 and maintained these behaviours into early May.

On the other hand, our results provide evidence of a reduction in macro-distancing behaviour between early April and May. In the longitudinal subsample, there was an increase in the number of people reporting 2-3 non-household contacts and a decrease in the number of people reporting 0 daily non-household contacts between Survey 1 and 2 (Figure 27.4). The easing of restrictions in both lower- and higher-impacted jurisdictions overlapped with the timing of Survey 2.

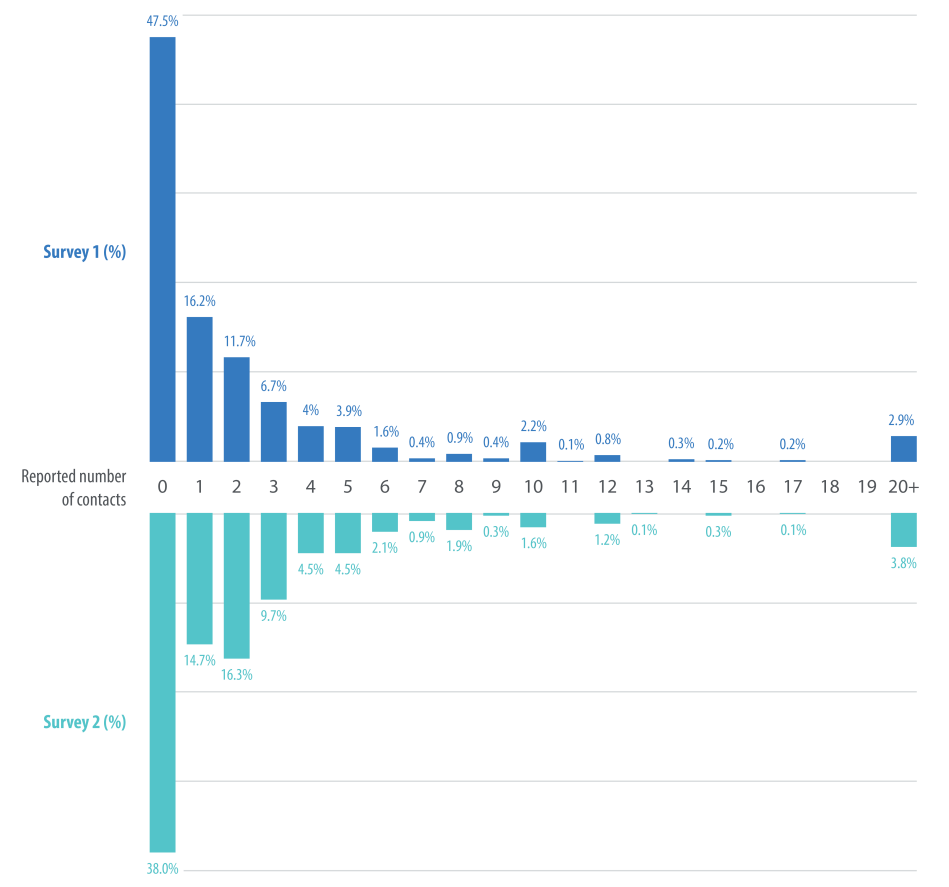

\section{FIGURE 27.4}

Reported number of non-household contacts at each Survey. A contact was "considered either a face to face conversation of a least three words or any form of physical contact, such as a handshake". Note that the bar charts are truncated at a maximum of 20 contacts, to better visualise spread values $>20$, which comprised only $3 \%$ of respondents. 
In both surveys, younger adults were more likely than older adults to report having a high number of contacts. However, the number of contacts was also linked to profession, with respondents working in health and medical services, air travel, restaurant services and retail more likely to report a high number of contacts outside of their household unit.

\subsubsection{How were people's concerns and perceptions related to their adherence to prevention measures?}

We examined how the change in reported perception of infection risk was associated with changes in the number of daily non-household contacts made and adherence to certain preventative measures. We report only associations between variables and make no attempt to infer causative relationships. For repeat respondents, the mean change in reported non-household contacts in the previous 24 hours showed an increase of 0.7 (95\% CI: -1.6, 3.0) additional contacts at Survey 2 compared to Survey 1. This varied by change in perceived risk of infection. At Survey 2, those who believed they were less likely to be infected had a mean reduction in non-household contacts (1.83 fewer contacts on average than Survey 1). This varied between lower-impacted ( 0.75 fewer contacts) and higher-impacted (2.54 fewer contacts) jurisdictions. Those who showed no change or an increase in perceived risk of infection at Survey 2, showed a slight increase in non-household contacts $(0.15$ additional contacts on average).

A univariate multinomial regression showed that those who said they were at lower risk of SARS-CoV-2 infection at Survey 2 had a 1.1-fold [95\% CI: 0.65, 1.86] increase in odds of reporting fewer non-household contacts at Survey 2 than those who reported no change in perceived risk of infection. Note that the wide confidence interval spanning 1 does not preclude the possibility of no effect or an effect in the opposite direction.

Analysis of the free text responses from Survey 2 showed a new (relative to Survey 1) and dominant theme linking community complacency, distancing, and a second wave of infections. Respondents were not so much blaming people, but suggesting that as time goes by there is a natural tendency to become complacent, contributing to a second wave, for example:

"Australians will become complacent, and the second wave of outbreaks will not be able to be controlled effectively."

Together with the quantitative findings of high levels of physical distancing behaviour, this suggests that some respondents were indeed maintaining distancing measures irrespective of the risk of personal infection: perhaps explained by their concern about the population (rather than personal) level implications of a second wave.

\subsubsection{What was the social and emotional impact of COVID-19?}

At both Surveys 1 and 2, a significant minority of respondents reported symptoms indicating high levels of anxiety $(24.2 \%$ and $19.9 \%$, respectively) and high levels of depressive symptoms $(17.5 \%$, and $17 \%$, respectively).

Conversely, 60.8\% (Survey 1) and $65.1 \%$ (Survey 2) of respondents were either somewhat or very optimistic about their future. People experiencing higher feelings of hope for their future were more likely to report lower levels of depression and anxiety.

In our longitudinal subsample, there was a statistically significant decrease in mean anxiety scores ${ }^{1}$ between Survey 1 (6.9) and Survey 2 (6.4). This result suggested that most survey respondents experienced a slight decrease in anxiety symptoms but remained in the normal range. However, the percentage of respondents who reported high levels of anxiety and may require professional mental health support increased between Survey 1 (15.4\%) and Survey $2(19.4 \%)$.

Free text responses revealed fewer expressions of worry about the pandemic between Surveys 1 and 2. At Survey 1, the dominant themes in concerns named by respondents were people, virus and

\footnotetext{
${ }^{1}$ As measured with the Hospital Anxiety and Depression Scale, out of a maximum of 21 points, scores between 0 and 7 are considered in the normal range, while cases with scores of 11 or above may require professional mental health support.
} 
health. "People" referred both to fears for the health of family and close friends, and concerns that not everyone was adopting distancing measures. Respondents used many different words expressing concern about economy, income and family and social factors. At Survey 2, people remained the dominant concern while the statements raising concerns about virus and health decreased in number. There was a large increase in the word "restriction", and more mentions of economy. At Survey 2, the words used to describe the virus were very different. There were fewer emotive statements about the scary or unknown characteristics of the virus. Although there were similar comments about spread in the virus compared with Survey 1, new concerns emerged about lack of herd immunity, winter coming in Australia, and a fear of a new spike or second wave. Some thought the health system would not be able to cope. Others had very serious personal concerns such as being about to give birth to their first child or the health of vulnerable family members.

\subsubsection{How did COVID-19 affect people's connection to others and people's connection to others influence their experience of COVID-19?}

At both surveys, higher levels of community connectedness were significantly associated with lower levels of depression and anxiety (see Table 27.3). Regarding social support, $68.7 \%$ (Survey 1) and $67.2 \%$ (Survey 2) of respondents said that they could rely on two people or more for assistance or support during the pandemic if they needed it. Meanwhile, 9.9\% (Survey 1) and $10.0 \%$ (Survey 2) reported that they had no one to rely on. These individuals may be at increased risk of negative mental health effects as higher levels of anxiety and depression were significantly associated with having fewer people to rely upon for assistance or support during the pandemic.

Additionally, 68.4\% (Survey 1) and $68.0 \%$ (Survey 2) of respondents said that two or more people relied on them for assistance or support during they pandemic. Those with more people who relied on them for assistance or support showed lower levels of anxiety and depression.

Free text responses in both surveys revealed evidence of altruism expressed in concerns for other groups of people, society in general and social justice. Respondents were concerned about "the loss of jobs of many vulnerable groups in the society, leading to unemployment and homelessness:" "temporary residents" and "survival of the less privileged in the society." Some said that while they were "financially OK," they were "concerned for the world in general and the impact on those who have lost more" leading to "an even larger gap between the rich and the poor." A small number of respondents were concerned for their employers:

"If I had to self-isolate, would have a dramatic impact on my employer; I would find that hard to deal with."

There were more responses about altruism and social justice in Survey 2 than in Survey 1, for example:

"I am fine. My biggest concern is for those who are not or will not be. That I will catch it without knowing and pass it on to the more vulnerable."

Some also spoke of concerns about domestic violence, aggressive behaviour and crime.

\subsubsection{Level of worry about the COVID-19 outbreak in Australia}

Respondents were asked to report their level of worry about the COVID-19 situation in Australia. Considering only those who responded to both surveys, the percentage of respondents who reported being worried about the COVID-19 outbreak in Australia decreased from 84.0\% at Survey 1 to $69.2 \%$ at Survey 2. This trend was consistent across lower- and higher-impacted jurisdictions.

Respondents who were less worried about the COVID-19 outbreak in Australia at Survey 2 (compared to Survey 1) had a mean increase in non-household contacts (1.37 more contacts), however respondents residing in higher-impacted jurisdictions had a smaller mean increase (0.56) compared to lower-impacted jurisdictions (2.35).

Respondents who were more worried about the COVID-19 outbreak in Australia had an 
overall mean decrease in contacts at Survey 2 (1.11 fewer contacts), however respondents residing in higher-impacted jurisdictions had a mean 2.44 fewer contacts and those in lower-impacted jurisdictions had a mean 1.75 more contacts.

We propose that individuals who were less worried once relative control of the epidemic was achieved (by the time of Survey 2), may have had lower levels of adherence to macro-distancing measures. Individuals who were more worried at Survey 2, appeared to be more cautious about making contacts. In both groups, individuals residing in higher-impacted jurisdictions made less contacts than those in lower-impacted jurisdictions, potentially reflecting different levels of restrictions. However, the easing of restrictions in both lower- and higher-impacted jurisdictions overlapped with the timing of Survey 2. It should be noted that our study does not distinguish between types of contacts (e.g., social versus workplace) and how "essential" these contacts might be deemed under different levels of restrictions: for example, the limited choices available to front line workers to reduce their contacts.

TABLE 27.1

Daily number of non-household contacts.

\begin{tabular}{lll}
\hline & $\begin{array}{l}\text { More worried } \\
\text { at Survey 2 }\end{array}$ & $\begin{array}{l}\text { Less worried } \\
\text { at Survey 2 }\end{array}$ \\
\hline Higher-impacted jurisdictions & 2.44 fewer & 0.35 more \\
Lower-impacted jurisdictions & 1.75 more & 2.35 more \\
Overall & 1.11 fewer & 1.37 more \\
\hline
\end{tabular}

\subsubsection{Perceptions of the future for Australia and the world}

At the time of data collection for Survey 2, the majority (95.4\%) of respondents were confident they could manage until the restrictions due to COVID-19 were over, however only $52.8 \%$ were confident that Australia could manage until the restrictions were over.

Feelings of confidence were also reflected in some of the answers to the survey's open question, for example: "I am feeling very confident that Australia has beaten this virus so am just looking forward to going out again."

High numbers of respondents in both Surveys provided free text responses criticising the behaviour of other people, suggesting some sort of moral, character or behavioural flaw. In Survey 1 there were more concerns about such behaviour: very many spoke of "Not adhering to rules" and a number about "Hoarding and panic buying". Concerns about behaviour were linked to the invisibility of the virus and young people's actions.

At Survey 2, 60.4\% of respondents were either somewhat or very optimistic about the future of Australia, and $47 \%$ felt the same way about the future of the world.

The answers to the survey's open question on people's biggest concern were not, however, all bleak. Some spoke of qualified hope or optimism, for example:

"I don't want to imagine anything negative right now, hope for the best."

"That we all stay positive"

Higher feelings of hope for the future of Australia and the world were significantly associated with lower levels of depression and anxiety. These results were consistent with Survey 1.

\subsubsection{Five elements to support people and communities confronted with disaster}

In this section, we summarise patterns of responses to the five elements to support people and communities confronted with large scale-disaster and loss in the immediate and mid-term [6]. We also explored how these five elements interact with people's mental health and wellbeing during pandemic restrictions.

Overall, we found that higher feelings of hope, connectedness, self and community efficacy, calm and safety were significantly associated with lower levels of anxiety and depression (Table 27.3). 
TABLE 27.2

Summarises patterns of responses to the five elements to support people and communities confronted with large scale-disaster and loss in the immediate and mid-term.

\begin{tabular}{|c|c|}
\hline Element & Findings \\
\hline Calm & $\begin{array}{l}\text { During both surveys, most poll respondents said that they could sit at ease and } \\
\text { feel relaxed }(66.1 \% \text { at Survey } 1 \text { and } 70.6 \% \text { at Survey } 2) \text {. }\end{array}$ \\
\hline Sense of safety & $\begin{array}{l}\text { The proportion of respondents who believed it was very likely or somewhat likely } \\
\text { that they would become infected with COVID-19 was } 38.2 \% \text { at Survey } 1 \text { and } 29.7 \% \\
\text { at Survey } 2 \text {. } \\
\text { In our longitudinal subsample, respondents' perceived likelihood of becoming } \\
\text { infected decreased between Surveys } 1 \text { and } 2 \text {. }\end{array}$ \\
\hline Efficacy & $\begin{array}{l}\text { Self-efficacy: during both surveys, most respondents felt they could manage until } \\
\text { restrictions due to COVID- } 19 \text { were over }(89.9 \% \text { at Survey } 1 \text { and } 68.1 \% \text { at Survey } \\
2 \text { ). Although the percentage of people who felt confident decreased between Survey } \\
1 \text { and } 2 \text {, respondents' mean scores in self-efficacy tended to increase. } \\
\text { Collective efficacy: the percentage of respondents who felt Australia could } \\
\text { manage until restrictions due to COVID-19 were over was lower at Survey } 2(77.4 \% \\
\text { at Survey } 1 \text { and } 52.8 \% \text { at Survey } 2) \text {. }\end{array}$ \\
\hline $\begin{array}{l}\text { Community } \\
\text { connectedness }\end{array}$ & $\begin{array}{l}\text { In Survey } 1, \text { out of a total score of } 30 \text { points, the mean score for community } \\
\text { connectedness }{ }^{*} \text { was } 22.36 \text { (standard deviation }=4.59 \text { ). Meanwhile, in Survey } 2 \text {, } \\
\text { the mean score was } 22.68 \text { (standard deviation }=4.54 \text { ). }\end{array}$ \\
\hline Hope & $\begin{array}{l}\text { About one's future: in Survey } 1,60.8 \% \text { of respondents were either somewhat or } \\
\text { very optimistic about their future, and } 65.1 \% \text { felt this way at Survey } 2 . \\
\text { About the future of Australia: in Survey } 1,56.5 \% \text { of respondents were either } \\
\text { somewhat or very optimistic about the future of Australia, and } 60.4 \% \text { felt this way } \\
\text { at Survey } 2 . \\
\text { About the future of the world: in Survey } 1,46 \% \text { of respondents were either } \\
\text { somewhat or very optimistic about the future of the world, and } 47 \% \text { felt this way } \\
\text { at Survey } 2 \text {. }\end{array}$ \\
\hline
\end{tabular}

* Measured with the Social Solidarity Index [30]

\section{TABLE 27.3}

Bivariate correlations (2-tailed) between the five elements of mid to long-term recovery[11] and levels of depression and anxiety measured with the Hospital Anxiety and Depression Scale (HADS)

\begin{tabular}{|c|c|c|c|c|}
\hline & \multicolumn{4}{|c|}{ Correlation $[95 \% \mathrm{CI}]$} \\
\hline & \multicolumn{2}{|c|}{ Anxiety } & \multicolumn{2}{|c|}{ Depression } \\
\hline & Survey 1 & Survey 2 & Survey 1 & Survey 2 \\
\hline Calm & $\begin{array}{c}-0.208 \\
{[-0.269,-0.147]}\end{array}$ & $\begin{array}{c}-0.202 \\
{[-0.264,-0.140]}\end{array}$ & $\begin{array}{c}-0.099 \\
{[-0.162,-0.037]}\end{array}$ & $\begin{array}{c}-0.126 \\
{[-0.189,-0.063]}\end{array}$ \\
\hline Sense of safety & $\begin{array}{c}-0.248 \\
{[-0.318,-0.179]}\end{array}$ & $\begin{array}{c}-0.225 \\
{[-0.292,-0.158]}\end{array}$ & $\begin{array}{c}-0.041 \\
{[-0.114,-0.032]}\end{array}$ & $\begin{array}{c}-0.132 \\
{[-0.201,-0.063]}\end{array}$ \\
\hline Self-efficacy & $\begin{array}{c}-0.204 \\
{[-0.265,-0.143]}\end{array}$ & $\begin{array}{c}0.046 \\
{[-0.015,0.108]}\end{array}$ & $\begin{array}{c}-0.261 \\
{[-0.321,-0.201]}\end{array}$ & $\begin{array}{c}0.060 \\
{[-0.002,0.121]}\end{array}$ \\
\hline Collective efficacy & $\begin{array}{c}-0.032 \\
{[-0.094,-0.030]}\end{array}$ & $\begin{array}{c}-0.039 \\
{[-0.101,0.022]}\end{array}$ & $\begin{array}{c}-0.099 \\
{[-0.161,-0.037]}\end{array}$ & $\begin{array}{c}-0.002 \\
{[-0.064,0.059]}\end{array}$ \\
\hline $\begin{array}{l}\text { Community } \\
\text { connectedness }\end{array}$ & $\begin{array}{c}-0.163 \\
{[-0.232,-0.095]}\end{array}$ & $\begin{array}{c}-0.168 \\
{[-0.239,-0.098]}\end{array}$ & $\begin{array}{c}-0.196 \\
{[-0.264,-0.129]}\end{array}$ & $\begin{array}{c}-0.254 \\
{[-0.322,-0.187]}\end{array}$ \\
\hline $\begin{array}{l}\text { Hope for one's } \\
\text { future }\end{array}$ & $\begin{array}{c}-0.251 \\
{[-0.313,-0.190]}\end{array}$ & $\begin{array}{c}-0.292 \\
{[-0.352,0.232]}\end{array}$ & $\begin{array}{c}-0.348 \\
{[-0.407,-0.288]}\end{array}$ & $\begin{array}{c}-0.381 \\
{[-0.439,-0.323]}\end{array}$ \\
\hline $\begin{array}{l}\text { Hope for the future } \\
\text { of Australia }\end{array}$ & $\begin{array}{c}-0.123 \\
{[-0.186,-0.060]}\end{array}$ & $\begin{array}{c}-0.170 \\
{[-0.232,-0.108]}\end{array}$ & $\begin{array}{c}-0.224 \\
{[-0.286,-0.162]}\end{array}$ & $\begin{array}{c}-0.249 \\
{[-0.310,-0.189]}\end{array}$ \\
\hline $\begin{array}{l}\text { Hope for the future } \\
\text { of the world }\end{array}$ & $\begin{array}{c}-0.059 \\
{[-0.123,0.005]}\end{array}$ & $\begin{array}{c}-0.127 \\
{[-0.189,-0.064]}\end{array}$ & $\begin{array}{c}-0.158 \\
{[-0.221,-0.095]}\end{array}$ & $\begin{array}{c}-0.183 \\
{[-0.244,-0.121]}\end{array}$ \\
\hline
\end{tabular}




\subsection{Discussion and conclusions}

In this chapter we have presented evidence to inform evolving COVID-19 response planning by analysing how Australians were thinking, feeling and behaving in response to the first wave of the COVID-19 epidemic and the associated public health measures. We explored these topics through an online survey of Australian adults $(\mathrm{N}=999)$ between 3-6 April, less than one week after "stay-at-home" restrictions were enacted nationally. To explore if and how people's thoughts, feelings, and behaviours may have changed over time, we fielded the same survey between 28 April and 6 May $(\mathrm{N}=1020)$, with 732 respondents completing both surveys.

High levels of adherence to physical distancing measures were reported in early April and high levels of micro-distancing behaviour (e.g., hand washing, staying $1.5 \mathrm{~m}$ from others) were maintained into May. There was some evidence of a decrease in macro-distancing behaviour (i.e., number of non-household contacts), which differed by jurisdiction and level of worry (see Table 27.1 for detail). Free text responses revealed fears that lockdown would be eased too early leading to a second wave. Added to concerns that people would become complacent, this suggests strong support for distancing measures.

While the level of worry about the pandemic in Australia decreased between early April and May 2020 overall, the group of individuals who reported increased levels of worry, reported lower rates of non-household contacts. This suggests that people's level of concern about the outbreak may impact their adoption of physical distancing behaviours. The trend was most marked for individuals residing in higher-impacted jurisdictions (New South Wales and Victoria). It should be noted that our study does not distinguish between types of contacts (e.g., social versus workplace) and how "essential" these contacts might be deemed under different levels of restrictions: for example, the limited choices available to front line workers.

Our findings are consistent with a number of other studies assessing people's response to COVID-19 public health measures. Recent studies conducted in China [31], Hong Kong [32], Japan [33], Korea [34], the Philippines [35], the United Kingdom [26], the United States [36], Germany, Italy and the Netherlands [37] report high levels of adoption of and broad support for physical distancing measures, during the period under study. Other studies conducted during/after the epidemics of severe acute respiratory syndrome (SARS) in 2003 [38], influenza A(H1N1)pdm09 in 2009 [39], and more recently, during the COVID-19 pandemic [40], have reported that higher levels of worry and/or perceived risk of infection were associated with the adoption of infection-prevention behaviours. However, it is important to also consider the influence of sense of self-efficacy on behaviours because previous evidence [41] shows that "when the threat was high as compared to low, people changed their behaviour in the advised direction only when efficacy was high, and not when efficacy was low". In fact, when efficacy was low, the behaviour change showed, if anything, an effect in the unhealthy direction" [42]. Further analyses are required to examine the relationship between the perception of risk, self- and community efficacy, and behaviour change [43]. At the time of writing, we did not identify any published longitudinal studies assessing how perceptions and behaviours may have changed during the course of the COVID-19 pandemic and response.

Since the success of physical distancing measures relies on people changing their behaviour, a challenge that lies ahead for policymakers is the potential for community fatigue. Individuals may not respond as quickly or assiduously if/when physical distancing measures are re-established in response to future outbreaks. Overall, our study found high levels of community acceptance of physical distancing measures. There was also evidence that distancing behaviours decreased between April and May; however, it is unclear whether this was due to reduced compliance or the easing of restrictions.

While physical distancing measures have proven highly effective at suppressing transmission of COVID-19 [44], they place a significant emotional and psychological burden on individuals, as highlighted by our study and others [45-47] — not to mention the economic consequences and potential longer-term health impacts. Governments around the world are currently grappling to balance the risks associated with an uncontrolled outbreak of COVID-19 against those associated with intensive and/or prolonged physical distancing measures. Studies such as ours can help to 
understand and guide the management of mental health risks associated with physical distancing measures.

Our findings about the association between mental health and sense of safety, calm, self and community efficacy, social connectedness and hope suggest ways forward in informing the public about support as communities emerge from pandemic restrictions. Previous evidence about use of fear to promote health behaviours [42] shows there is a risk in conveying the seriousness of the health risk unless it is accompanied by messages that promote sense of self- and community efficacy. Our qualitative data also suggested levels of hope, altruism, and trust in science counterbalance difficult decisions and bad news. At the same time, previous studies have shown that individual and community empowerment must go beyond promoting feelings of competence - they require having access to and control over the resources in one's environment $[48,49]$. In line with this, we argue that policies and services that support people experiencing economic adversity (such as Australia's income support payments "JobSeeker" and "JobKeeper" [50]), and those associated with childcare, mental health and family violence can be a crucial source of individual and community resilience during the response and recovery phases of the pandemic.

Other studies conducted during COVID-19 have found that access to reliable health information and precautionary measures like hand hygiene and wearing a mask was associated with lower levels of emotional distress $[45,51]$. In our study, having a larger number of people to rely on for assistance or support or being the source of assistance or support for other people was associated with lower levels of anxiety and depression, highlighting the importance of social connections for supporting mental health and wellbeing. Our findings are consistent with previous evidence about the human impacts of disasters, including the COVID-19 pandemic, and show how important it is to find ways to maintain social connections while following the physical distancing guidelines. Since pandemics have the potential to perpetuate and exacerbate existing social disparities [52], the social structures of populations most at risk of negative outcomes from the disease and/or transmission-mitigating policies, should be closely considered if the goal is an equitable response strategy.

Our study was necessarily rapidly conceived and implemented in response to the evolving epidemiological and policy situation in Australia. While useful for gaining rapid insights into people's feelings and behaviours, our results need to be interpreted in the context of the limitations of the research design. The sampling strategy did not allow for surveying individuals without internet access, low literacy or limited English language skills, or communication or cognitive difficulties. Additionally, people who register to complete YouGov surveys may also be different from the general population in ways that we cannot identify. Subgroup analyses may be limited by smaller participant numbers; and qualitative data was from one free text response, limiting potential analyses.

In conclusion, studies such as this are necessarily conducted with short lead times and rely on the skills and capacity of public health researchers to work quickly within resource constraints. We therefore offer reflections and recommendations for research design in this and other pandemics. A formal and collegial review of studies to date would also be prudent, so we can learn and make methodological suggestions for future rapid onset research.

Studies such as ours provide broad, population-level insights, and near-real-time data for estimating transmission potential and forecasting epidemic activity [29]. COVID-19 epidemiology and response policy will continue to change rapidly over the coming months and years. In order to capture/monitor associated shifts in people's feelings and behaviours, public health researchers should plan flexible studies where data collection (repeated cross-sectional or longitudinal) is timed to occur in response to key changes in epidemiology and public health policy. Data collection and participant recruitment methods should ensure the representation of higher-transmission groups, in terms of their demography and geography.

Ultimately, more in-depth studies of the social, emotional and behavioural dimensions of physical distancing should be conducted to supplement findings from structured online surveys. These studies may include less structured interviews and/or surveys with more opportunities for individuals to respond in their own words. Follow-up studies should also target population groups most impacted by COVID-19 - in terms of disease outcomes and restrictions - in order to understand what different groups may need to help them to follow public health guidelines and to support the development of tailored and targeted public health policy. For example, this 
may include exploring the potential barriers to cooperating with physical distancing, isolation, and quarantine regulations experienced by individuals with insecure employment or higher-density housing conditions.

\subsection{COVID-19 Developments and Further Research}

In late June 2020, the state of Victoria experienced a significant resurgence of COVID-19 epidemic activity. By late July, daily case counts reached nearly 20 times those seen in March and stay-at-home restrictions had been reinstated across Victoria [53].

The epidemiology of Victoria's second COVID-19 incursion has been distinct from the first. While caseloads in March and April were dominated by overseas acquired infections, the June outbreak has seen the establishment of community transmission, and heightened transmission within groups that are less able to practice physical distancing (e.g., healthcare workers, public housing residents including communities from migrant and refugee backgrounds and residents of aged care facilities). At the time of writing, a third survey of Victorian residents, including interviewer-assisted surveys of individuals from migrant and refugee backgrounds, was in progress to help inform the State's response.

Insights from this study have been considered by various policy and strategy structures and this chapter, along with further analyses, can help to inform public health planning for the management of COVID-19 and other diseases of epidemic potential.

\section{Acknowledgements}

The authors acknowledge funding support from the Melbourne School of Population and Global Health, The University of Melbourne. We also thank Professors Nancy Baxter and Jodie McVernon for their support of this project.

\section{References}

[1] World Health Organization. Novel Coronavirus (2019-nCoV) Situation Report - 1. 2020. URL https://www. who. int/docs/default-source/coronaviruse/situation-reports/20200121-sitrep-1-2019ncov.pdf?sfvrsn=20a99c10_4. Accessed on September 24, 2020.

[2] Andrea Remuzzi and Giuseppe Remuzzi. COVID-19 and Italy: what next? The Lancet, 395(10231):1225-1228, 2020. doi: 10.1016/S0140-6736(20)30627-9.

[3] The Lancet. COVID-19 in the USA: a question of time. Lancet, 395(10232):1229, 2020. doi: 10.1016/S01406736(20)30863-1.

[4] Australian Government Department of Health. Australian Health Management Plan for Pandemic Influenza.

[5] Qualls N, Levitt A, Kanade N, Wright-Jegede N, Dopson S, Biggerstaff M, and Reed C UA. Community Mitigation Guidelines to Prevent Pandemic Influenza-United States. MMWR Recomm Rep. 2017;66(No. $R R$-1):1-34. URL http://www.cdc.gov/mmwr/cme/conted.html.

[6] Public Health England. Pandemic Influenza Response Plan.

[7] Ministry of Health Labour and Welfare of Japan. National Action Plan for Pandemic Influenza and New Infectious Diseases.

[8] Ministry of Health Singapore. MOH Pandemic Readiness and Response Plan For Influenza and Other Acute Respiratory Diseases. URL https://www.moh.gov.sg/docs/librariesprovider5/diseases-updates/interimpandemic-plan-public-ver-_april-2014.pdf. Accessed on October 18, 2020. 
[9] Shearer FM, Gibbs L, Alisic E, and et al. Distancing Measures in the Face of COVID-19 in Australia. Summary of National Survey Findings. Survey 2 Report, 2020. URL https://www.doherty.edu.au/uploads/ content_doc/social_distancing_survey_wave1_report_May142.pdf. Accessed on September 24, 2020.

[10] Meagher N, Carpenter L, Chavez KM, and et al. Distancing Measures in the Face of COVID-19 in Australia. Summary of National Survey Findings: Survey Wave 1., 2020. URL https://www.doherty.edu.au/uploads/ content_doc/Covid_report_2.pdf. Accessed on September 24, 2020.

[11] S Hobfoll, P Watson, C Bell, R Bryant, M Brymer, M Friedman, et al. Five essential elements of immediate and mid-term mass trauma intervention: empirical evidence. Psychiatry, 70(4):283-315. doi: 10.1521/psyc. 2007.70.4.283.

[12] Australian Red Cross. Psychological First Aid: An Australian guide to supporting people affected by disaster. Published 2013. URL https://www.psychology.org.au/getmedia/c1846704-2fa3-41ae-bf53-7a7451af6246/Redcrosspsychological-first-aid-disasters.pdf. Accessed on September 24, 2020.

[13] World Health Organization. War Trauma Foundation and World Vision International. Psychological first aid: Guide for field workers. URL https://apps.who.int/iris/bitstream/handle/10665/44615/9789241548205_eng. pdf; jsessionid=8B079EB2CED837997893970749D3ED67?sequence=1. Accessed on September 24, 2020.

[14] COVID-19 National Incident Room Surveillance Team. 2019-nCoV acute respiratory disease, Australia: Epidemiology Report 1 (Reporting week 26 January - 1 February 2020). Communicable Diseases Intelligence, 44, 2020. doi: 10.33321/cdi.2019.44.13.

[15] COVID-19 National Incident Room Surveillance Team. COVID-19, Australia: Epidemiology Report 2 (Reporting week ending 19:00 AEDT 8 February 2020). Commun Dis Intell, 44, 2020. doi: 10.33321/ cdi.2020.44.14.

[16] World Health Organization. Coronavirus disease 2019 (COVID-19). Situation Report - 41, 2020. URL https://www. who.int/docs/default-source/coronaviruse/situation-reports/20200301-sitrep-41-covid19.pdf?.sfvrsn=6768306d_2. Accessed on September 24, 2020.

[17] COVID-19 National Incident Room Surveillance Team. COVID-19, Australia: Epidemiology Report 12 (Reporting week ending 23:59 AEST 19 April 2020). Commun Dis Intell - 44, 2020.

[18] COVID-19 National Incident Room Surveillance Team. COVID-19, Australia: Epidemiology Report 9 (Reporting week to 23:59 AEDT 29 March 2020). Commun Dis Intell, 44, 2020. doi: 10.33321/cdi.2020.44.29.

[19] Raj Dandekar, Shane G Henderson, Hermanus M Jansen, Joshua McDonald, Sarat Moka, Yoni Nazarathy, Christopher Rackauckas, Thomas M Stace, Peter G Taylor, and Aapeli Vuorinen. Early analysis of the australian covid-19 epidemic. Elife, 9:1-14, 2020. doi: 10.7554/ELIFE.58785.

[20] COVID-19 National Incident Room Surveillance Team. COVID-19, Australia: Epidemiology Report 16: Reporting week ending 17 May 2020. Commun Dis Intell, 44, 2020.

[21] Government of Western Australia. Media statement: Cautious easing of restrictions thanks to WA's COVID-19 progress. 2020. URL https://www.mediastatements.wa.gov.au/Pages/McGowan/2020/04/Cautious-easing-ofrestrictions-thanks-to-WAs-COVID-19-progress.aspx. Accessed on September 24, 2020.

[22] Northern Territory Government. Media statement: The Territory's Roadmap to the New Normal. 2020. URL https://coronavirus.nt.gov.au/updates/items/2020-04-30-the-territorys-roadmap-to-the-new-normal. Accessed on September 24, 2020.

[23] New South Wales Government. Media statement: Update on COVID-19 restrictions. 2020. URL https: //www.nsw.gov.au/media-releases/update-on-covid-19-restrictions. Accessed on September 24, 2020.

[24] COVID-19 National Incident Room Surveillance Team. COVID-19, Australia: Epidemiology Report 19 (Fortnightly reporting period ending 21 June 2020). Commun Dis Intell, 44, 2020. doi: 10.33321/cdi.2020. 44.54 .

[25] O'Brien T. Coronavirus (COVID-19) in Australia. 2020. URL https://www.covid19data.com.au/. Accessed on September 24, 2020.

[26] Christina J Atchison, Leigh Bowman, Charlotte Vrinten, Rozlyn Redd, Philippa Pristera, Jeffrey W Eaton, and Helen Ward. Perceptions and behavioural responses of the general public during the COVID-19 pandemic: A cross-sectional survey of UK Adults. medRxiv, 1-21, 2020. doi: 10.1101/2020.04.01.20050039.

[27] Ritchie J and Spencer L. Qualitative data analysis for applied policy research. In: Bryman A, Burgess RG, eds). Analysing Qualitative Data. London: Routledge; 1994:173-194, 2020.

[28] Annemarie B Docherty, Ewen M Harrison, Christopher A Green, Hayley E Hardwick, Riinu Pius, Lisa Norman, Karl A Holden, Jonathan M Read, Frank Dondelinger, Gail Carson, et al. Features of 20133 uk patients in hospital with covid-19 using the isaric who clinical characterisation protocol: prospective observational cohort study. bmj, 369:m1985, 2020. doi: 10.1136/bmj.m1985.

[29] Golding N, Shearer FM, Moss R, and et al. Estimating Temporal Variation in Transmission of SARS-CoV-2 and Physical Distancing Behaviour in Australia). 2020. 
[30] Pekka Räsänen, James Hawdon, Matti Näsi, and Atte Oksanen. Social solidarity and the fear of risk: Examining worries about the recurrence of a mass tragedy in a small community. Sociological Spectrum, 34, 06 2014. doi: 10.1080/02732173.2014.917248.

[31] Jing Huang, Fangkun Liu, Ziwei Teng, Jindong Chen, Jingping Zhao, Xiaoping Wang, Ying Wu, Jingmei Xiao, Ying Wang, and Renrong Wu. Public behavior change, perceptions, depression, and anxiety in relation to the covid-19 outbreak. Open forum infectious diseases, 7(8):ofaa273-ofaa273, 2020. ISSN 2328-8957. doi: 10.1093/ofid/ofaa273.

[32] Emily Ying Yang Chan, Zhe Huang, Eugene Siu Kai Lo, Kevin Kei Ching Hung, Eliza Lai Yi Wong, and Samuel Yeung Shan Wong. Sociodemographic predictors of health risk perception, attitude and behavior practices associated with health-emergency disaster risk management for biological hazards: The case of COVID-19 pandemic in Hong Kong, SAR China. Int J Env Res Public Heal, 17(11):1-18, 2020. doi: 10.3390/ijerph17113869.

[33] Kaori Muto, Isamu Yamamoto, Miwako Nagasu, Mikihito Tanaka, and Koji Wada. Japanese citizens' behavioral changes and preparedness against COVID-19: An online survey during the early phase of the pandemic. Plos one, 15(6):e0234292, 2020. URL https://doi.org/10.1371/journal.pone.0234292.

[34] Jang WM, Jang DH, and Lee JY. Social distancing and transmission-reducing practices during the 2019 coronavirus disease and 2015 middle east respiratory syndrome coronavirus outbreaks in Korea. J Korean Med Sci, 35(23):e220, 2020. doi: 10.3346/JKMS.2020.35.E220.

[35] Lincoln Leehang Lau, Natalee Hung, Daryn Joy Go, Jansel Ferma, Mia Choi, Warren Dodd, and Xiaolin Wei. Knowledge, attitudes and practices of COVID-19 among income-poor households in the Philippines: A cross-sectional study. Journal of global health, 10(1), 2020. doi: 10.7189/JOGH.10.011007.

[36] Mark É Czeisler, Michael A Tynan, Mark E Howard, Sally Honeycutt, Erika B Fulmer, Daniel P Kidder, Rebecca Robbins, Laura K Barger, Elise R Facer-Childs, Grant Baldwin, et al. Public Attitudes, Behaviors, and Beliefs Related to COVID-19, Stay-at-Home Orders, Nonessential Business Closures, and Public Health Guidance - United States, New York City, and Los Angeles, May 5-12, 2020. MMWR Morbidity and Mortality Weekly Report, 69(24):751-758, 2020. doi: 10.15585/mmwr.mm6924e1.

[37] Karien Meier, Toivo Glatz, Mathijs C Guijt, Marco Piccininni, Merel van der Meulen, Khaled Atmar, Anne-Tess C Jolink, Tobias Kurth, Jessica L Rohmann, Amir H Zamanipoor Najafabadi, et al. Public perspectives on protective measures during the COVID-19 pandemic in the Netherlands, Germany and Italy: A survey study. PloS one, 15(8):e0236917, 2020. doi: 10.1371/journal.pone.0236917.

[38] JTF Lau, X Yang, H Tsui, and JH Kim. Monitoring community responses to the SARS epidemic in Hong Kong: From day 10 to day 62. J Epidemiol Community Heal, 57(11):864-870, 2003. doi: 10.1136/jech.57.11.864.

[39] James Holland Jones and Marcel Salathe. Early assessment of anxiety and behavioral response to novel swine-origin influenza A (H1N1). PLoS one, 4(12):2-9, 2009. doi: 10.1371/journal.pone.0008032.

[40] Holly Seale, Anita E Heywood, Julie Leask, Meru Steel, Susan Thomas, David N Durrheim, Katarzyna Bolsewicz, and Rajneesh Kaur. COVID-19 is rapidly changing: Examining public perceptions and behaviors in response to this evolving pandemic. PLoS One, 6(15):e0235112, 2020. doi: 10.1371/journal.pone.0235112.

[41] Gjalt-Jorn Y Peters, Robert Ruiter, and Gerjo Kok. Threatening communication: a critical re-analysis and a revised meta-analytic test of fear appeal theory. Health Psychol Rev. 7(Suppl 1):S8-S31, 2013. doi: $10.1080 / 17437199.2012 .703527$.

[42] Gerjo Kok, Gjalt-Jorn Y Peters, Loes TE Kessels, Gill A Ten Hoor, and Robert AC Ruiter. Ignoring theory and misinterpreting evidence: the false belief in fear appeals. Health Psychology Review, 12(2):111-125, 2018. doi: $10.1080 / 17437199.2017 .1415767$.

[43] Bavel JJ Van, Baicker K, Boggio PS, and et al. Using social and behavioural science to support COVID-19 pandemic response. Nat Hum Behav. 4(5):460-471., 2020. doi: 10.1038/s41562-020-0884-z.

[44] Flaxman S, Mishra S, Gandy A, and et al. Estimating the effects of non-pharmaceutical interventions on COVID-19 in Europe. Nature, 584(7820):257-261, 2020. doi: 10.1038/s41586-020-2405-7.

[45] Nadia Yanet Cortés-Álvarez, Regino Piñeiro-Lamas, and César Rubén Vuelvas-Olmos. Psychological effects and associated factors of covid-19 in a mexican sample. Disaster Med Public Health Prep, pages 1-12, 2020. doi: $10.1017 / \mathrm{dmp} .2020 .215$.

[46] Brett Marroquín, Vera Vine, and Reed Morgan. Mental health during the COVID-19 pandemic: Effects of stay-at-home policies, social distancing behavior, and social resources. Psychiatry Res, 293, 2020. doi: 10.1016/j.psychres.2020.113419.

[47] Matthew T Tull, Keith A Edmonds, Kayla Scamaldo, Julia R Richmond, Jason P Rose, and Kim L Gratz. Psychological outcomes associated with stay-at-home orders and the perceived impact of covid-19 on daily life. Psychiatry Res, 289, page 113098, 2020. doi: 10.1016/j.psychres.2020.113098.

[48] Danielle Kohfeldt, Lina Chhun, Sarah Grace, and Regina Day Langhout. Youth empowerment in context: Exploring tensions in school-based yPAR. Am J Community Psychol, 47(1-2):28-45, 2011. doi: 10.1007/ s10464-010-9376-z. 
[49] Julian Rappaport. In praise of paradox: A social policy of empowerment over prevention. Am J Community Psychol, 9(1):1, 1981. doi: 10.1007/bf00896357.

[50] Australian Government. Payments and services during coronavirus (COVID-19).

[51] C Wang, R Pan, X Wan, et al. Immediate Psychological Responses and Associated Factors during the Initial Stage of the 2019 Coronavirus Disease (COVID-19) Epidemic among the General Population in China. Int $J$ Env Res Public Heal, 17(5), 2020. doi: 10.3390/ijerph17051729.

[52] Debruin D, Liaschenko J, and Marshall MF. Social Justice in Pandemic Preparedness Social Justice in Pandemic Preparedness. Am J Public Heal, 102(4):586-591, 2012. doi: 10.2105/AJPH.

[53] COVID-19 National Incident Room Surveillance Team. COVID-19, Australia: Epidemiology Report 21: Fortnightly reporting period ending 19 July 2020. Commun Dis Intell, 44, 2020. 